\title{
BMJ open Exploring the potential of expatriate social networks to reduce HIV and STI transmission: a protocol for a qualitative study
}

\author{
Gemma Crawford, ${ }^{1}$ Nicole Jasmine Bowser, ${ }^{1}$ Graham Ernest Brown, ${ }^{2}$ \\ Bruce Richard Maycock ${ }^{3}$
}

To cite: Crawford G, Bowser NJ, Brown GE, et al. Exploring the potential of expatriate social networks to reduce HIV and STI transmission: a protocol for a qualitative study. BMJ Open 2013;3:e002581.

doi:10.1136/bmjopen-2013002581

- Prepublication history for this paper are available online. To view these files please visit the journal online (http://dx.doi.org/10.1136/ bmjopen-2013-002581).

Received 18 January 2013 Accepted 28 January 2013

This final article is available for use under the terms of the Creative Commons Attribution Non-Commercial 2.0 Licence; see http://bmjopen.bmj.com

\section{${ }^{1}$ Western Australian Centre for Health Promotion Research, Curtin Health Innovation Research Institute, Curtin University, Perth, Western Australia, Australia ${ }^{2}$ Australian Research Centre in Sex Health and Society, La Trobe University, Melbourne, Victoria, Australia ${ }^{3}$ School of Public Health, Curtin University, Perth, Western Australia, Australia}

Correspondence to Gemma Crawford; g.crawford@curtin.edu.au

\section{ABSTRACT}

Introduction: HIV diagnoses acquired among Australian men working or travelling overseas including Southeast Asia are increasing. This change within transmission dynamics means traditional approaches to prevention need to be considered in new contexts. The significance and role of social networks in mediating sexual risk behaviours may be influential. Greater understanding of expatriate and traveller behaviour is required to understand how local relationships are formed, how individuals enter and are socialised into networks, and how these networks may affect sexual intentions and behaviours. This paper describes the development of a qualitative protocol to investigate how social networks of Australian expatriates and long-term travellers might support interventions to reduce transmission of HIV and sexually transmitted infections.

Methods and analysis: To explore the interactions of male expatriates and long-term travellers within and between their environments, symbolic interactionism will be the theoretical framework used. Grounded theory methods provide the ability to explain social processes through the development of explanatory theory. The primary data source will be interviews conducted in several rounds in both Australia and Southeast Asia. Purposive and theoretical sampling will be used to access participants whose data can provide depth and individual meaning.

Ethics and dissemination: The role of expatriate and long-term traveller networks and their potential to impact health are uncertain. This study seeks to gain a deeper understanding of the Australian expatriate culture, behavioural contexts and experiences within social networks in Southeast Asia. This research will provide tangible recommendations for policy and practice as the findings will be disseminated to health professionals and other stakeholders, academics and the community via local research and evaluation networks, conference presentations and online forums. The Curtin University Human Research Ethics Committee has granted approval for this research.

\section{ARTICLE SUMMARY}

Article focus

- Qualitative exploration.

- Role of expatriates and longer term travellers as mentors and change agents.

- Deeper contextual understanding of culture, personal behaviours, socialisation process and pathways.

Key messages

- Untested area which will provide context and tangible outcomes for research, policy and practice.

- Determine the potential of social networks to support peer and social influence interventions to reduce HIV and STI transmission.

- Gain insight into expatriate and long-term traveller behaviour.

Strengths and limitations of this study

- Opportunity to develop novel ways of thinking and sense making about changes to the HIV epidemic.

- Challenges in recruiting participants owing to cross-country (distance, resources) and crosscultural (language, culture, beliefs and stigma) considerations.

\section{INTRODUCTION}

Internationally recognised for its response to the HIV epidemic, Australia has demonstrated strong partnerships, high levels of investment, action by affected communities and utilisation of peer and social influence in prevention. ${ }^{1}{ }^{2}$ However, changing transmission dynamics $\begin{array}{llllll}1 & 3 & 4 & \text { mean these }\end{array}$ approaches need to be considered in new contexts. Australian data point to an increasing number of diagnoses of HIV among men, acquired while working or travelling overseas, including among heterosexual men. ${ }^{5}$ People who travel to and from countries with high HIV prevalence have been 
identified as a priority population in the National HIV Strategy 2010-2013. ${ }^{1}$

Over the past decade, there has been an upward trend of overseas-acquired HIV notifications in Western Australia. The number of Western Australians acquiring HIV overseas increased from 97 people during the 5 -year period from 2001 to 2005 to 227 people from 2006 to $2010 .{ }^{4}$ Surveillance demonstrates that a proportion of these new HIV infections have occurred in Southeast Asia, particularly Thailand and Indonesia. ${ }^{4} 6$ This has occurred concurrently with an increase in travel to this region. ${ }^{7}$ Thailand and Indonesia are the countries most frequented by Australian travellers, with a $3.3 \%$ increase in travel to Indonesia and $2.6 \%$ increase in travel to Thailand since $2001 .{ }^{7}$ Over the same time period, travel to destinations such as New Zealand and the USA decreased. ${ }^{7}$

Recent research by Brown $e t a l^{8}$ indicates that increases in HIV prevalence may be linked to factors including a strong mining industry with associated travel and high incomes, and strong expatriate cultures and networks which exist outside Australia. This is supported by findings from a national seroconversion study reporting that one in six men interviewed had experienced a high-risk event overseas, with a third of these events occurring in Asia. ${ }^{9}$ Of those men, two-thirds were living or working in Asia at the time of the high-risk event and almost $40 \%$ had been there for more than a year. However, for around a third of those interviewed, the occasion of the high-risk event was their first visit to the country. ${ }^{9}$

The impact of transport infrastructure, frequent and cheap plane travel and tourism have been drivers of the rapid global growth of HIV and sexually transmitted infection (STI) rates. ${ }^{10}$ In many regions, the interplay between sex and alcohol and other drug use in risktaking behaviour amplifies the effects of the epidemics. ${ }^{11}$ A region to experience these effects is one of Australia's nearest neighbours, Southeast Asia, particularly Thailand which continues to experience high rates of HIV among people who inject drugs (PWIDs), informal sex workers and men who have sex with men (MSM) ${ }^{412}$

While there is a body of literature on the relationship between sex and travel, much is historical. Research with expatriates posted to HIV-prevalent areas has shown inconsistent condom use and poor estimated prevalence of HIV in the destination country. ${ }^{13}$ Additionally, studies found that casual and unprotected sex were reasonably common among expatriates as was the use of commercial sex services. ${ }^{13} 14$

A contemporary meta-analysis also demonstrated that those staying abroad for longer periods may be more likely to engage in new sexual relationships and casual sex, including seeking commercial sex. ${ }^{15}$ A recent study of Japanese tourists found that some of the main reasons for seeking commercial sex included the anonymity and sense of freedom, being lonely and the influence of peers, along with the availability of sexual services that were relatively inexpensive. ${ }^{16}$ Additionally, research in Thailand found that longer term intimacy formed between travellers and expatriates and local 'bar girls' who may have one or more concurrent partner, blurring the line between 'relationship' and commercial transaction. ${ }^{17}$

The significance and role of social networks may mediate sexual risk behaviours. Brown et a $\ell^{\S}$ found that networks among expatriates and frequent travellers potentially created strong social norms regarding a range of attitudes and behaviour related to HIV and STIs. Engaging with and utilising the social networks of expatriate and long-term travellers may provide assets for interventions, but a comprehensive and clear understanding of how these networks operate is required to be effective. ${ }^{8}$

Tucker $e t a l^{18}$ suggest that analysis of networks can identify social factors relevant to risk behaviours and reveal characteristics of networks that can be used to develop innovative and effective interventions. Peer and social influence have been dominant approaches in HIV prevention, particularly within Australia, in often marginalised groups such as sex workers, PWIDs and gay, bisexual and other MSM. ${ }^{8} 19{ }^{20}$ Programmes employing these methods access key individuals who are members of groups or networks engaging in risk behaviours and use them to disseminate prevention messages and promote behaviour change. ${ }^{12} 181921$

Greater understanding is required of the context of expatriate and traveller behaviour. There is a lack of knowledge of how local relationships are formed, how individuals enter and are socialised into networks, and the effects that these social networks have on the sexual intentions and behaviours of expatriates and long-term travellers. This paper describes the development of a protocol to investigate how social networks formed among the Australian expatriates can be used to develop effective interventions. This study builds on recent research, seeking to gain a deeper understanding of the Australian expatriate culture, behavioural contexts and experiences within social networks in Southeast Asia to guide further research, policy and practice.

\section{METHODS AND ANALYSIS}

\section{Conceptual framework}

This research is interested in the development of self and self-identity, which occur within and between the interactions of male expatriates and long-term travellers and their environment. This domain of enquiry is consistent with the theoretical perspectives of symbolic interactionism, ${ }^{22}$ which is based on the subjective meaning that individuals attribute to their own actions and to how they interpret and interact with the world around them. ${ }^{23}$ The benefit of utilising this perspective as part of the research framework is to provide an opportunity to look for culturally derived and historically situated interpretations of the world from the expatriate point of view, and to record how individuals end up assuming an expatriate identity. ${ }^{24}$ 
The research seeks to examine the transition process from Australian to Expatriate Australian and Insider in the expatriate and local community. The development of self, social processes and pathways and the impact of culture will be investigated along with the relationship between expatriates, the environment and the different communities they engage with. ${ }^{25} 26$ The concept of culture used in this study is taken from the symbolic interaction perspective as used by Charon ${ }^{23}$ and includes the use of significant symbols and ritual. ${ }^{27}$

\section{Methodology}

The methodological approach chosen for this research is grounded theory ${ }^{28-30}$ because the 'emphasis is on process, theoretical sensitivity and the centrality of a storyline around which analysis can coalesce'. ${ }^{31}$ The use of grounded theory provides the researcher with a level of reflexivity ${ }^{25}$ that is particularly valuable in the current context of cross-cultural research. The use of constant comparison of data as they are collected and analysed enables themes to emerge that become more focused and theoretical as the research progresses. ${ }^{25}$

The grounded theory methods provide the ability to explain social processes through the development of explanatory theory. ${ }^{32}$ It is a useful complement to the use of symbolic interactionism as both derive from similar epistemological and ontological perspectives. ${ }^{29}$ The combination of symbolic interactionism and grounded theory as theoretical framework and methodology has been successfully used in previous HIV social research. ${ }^{8} 26$

\section{Assessing methodological quality}

The consolidated criteria for reporting qualitative research $(\text { COREQ })^{33}$ will be used to ensure that this study meets appropriate standards for qualitative research. ${ }^{34}$ While wellknown tools exist to assess the quality of quantitative research, ${ }^{35}$ similar tools for use in qualitative studies are less common. ${ }^{36}$ Criteria were developed to address the lack of comprehensive frameworks to assess the quality of qualitative research for publication. ${ }^{33}$ The tool is a 32-item checklist grouped into several key areas: research team and reflexivity, the study design and data analysis and reporting. ${ }^{33}$ The criteria have been used with a range of studies to enhance their rigour. ${ }^{37-39}$ Use of the COREQ tool will be explored in detail when field-testing the protocol.

\section{Aim and objectives}

The primary aim of this study is to determine whether the social networks of Australian male expatriates in Southeast Asia have the potential to support peer and social influence interventions to reduce the transmission of HIV and STI. Specifically, the research seeks to build a deeper contextual understanding of culture and personal behaviours, describe the socialisation process and pathways and investigate the roles of Australian expatriates and long-term travellers as mentors and change agents within their social networks.
Recommendations will be made for further research, policy and interventions targeting expatriates and frequent or longer term travellers.

For the purposes of this research, an expatriate is defined as: someone who has taken up a paid work position within an organisation in Southeast Asia for a period of more than 6 months. A long-term traveller is defined as: someone who has spent more than 6 months within a 12-month period in Southeast Asia.

\section{Setting}

This research will take place primarily within Western Australia with additional data collected in the Northern Territory and Thailand. These locations were chosen owing to previously established networks and because of the patterns of overseas acquired diagnoses of HIV. Online settings such as expatriate forums will also be utilised. Anecdotally, these sites experience significant use by current and potential expatriates and may provide opportunities to recruit participants. The experiences of participants recruited via online networks will be compared to those of participants recruited through other avenues to explore similarities and differences. Thailand-based research will include interviews within bars and other entertainment venues as well as an audit of key night locations as recommended by Brown et al Stakeholder interviews will be conducted in places of business including departments of health, universities, HIV organisations and other non-government organisations.

\section{Research team}

A steering group will be convened for this research project. This will comprise both researchers and practitioners who will provide expertise on social groups and networks, risk-taking behaviour, HIV and other STIs and include those who have experience in conducting research in Southeast Asia. The reference group will also include expatriates who have participated in earlier research, including those who have acquired HIV, now living in Australia. It is envisioned that a small proportion of the key informants who will be interviewed may be drawn from this group. The group will provide an opportunity to reflect on and refine themes throughout the research process, provide research direction, ensure rigour, triangulate data and manage ethical considerations. ${ }^{32} 3640$

The team undertaking the research in Thailand will comprise female and male researchers and practitioners drawn from the research steering group including university-based research staff and staff from state and national HIV organisations with experience in working with the community and engaging organisations in Thailand. This small 'away' team will enable consideration of issues including the most appropriate gender to conduct the interview, most appropriate role or organisational seniority level to lead interviews, as well as safety considerations. The team will also provide support for in-country reflection and direction for data collection. The need to have multiple data collectors in the 'away' 
team will require a high level of management and a coordinated approach to the data collection process. To strengthen this process, dedicated time will be spent with the research team before trips to Thailand and in a scheduled debriefing throughout the time away.

\section{Sample selection, recruitment and size}

Purposive and theoretical sampling will be used to access participants whose information can provide depth, detail and individual meaning. ${ }^{41}{ }^{42}$ The expertise of those participants familiar with expatriate culture will guide the research. Several types of participants will be recruited including those who can provide personal accounts of living as an expatriate or long-term traveller as well as participants whose role will assist to identify expatriate networks.

\section{Selection}

To participate in this study, participants must be either:

A. Men over the age of 18 and either a current or past expatriate or a long-term traveller to Southeast Asia. Interviews will be conducted with a range of men including expatriates from Australia working in the entertainment industry (bars/clubs), those working in other contexts including professionals, men working in mining/resources or aid workers or expatriates and longer term travellers from Australia travelling to and from Southeast Asia for pleasure, work or both.

B. Key informants from agencies and organisations who can provide context for this research and provide contacts for expatriate networks. Western Australian and Southeast Asian-based community, government and business organisations will be used to source these key contacts for interviews. Participants may be of any gender but will all be over 18 years of age.

\section{Recruitment}

Participants will be recruited via phone, email and online expatriate forums. Initial recruitment will focus on research participants in Western Australia and Thailand drawn from existing networks developed through previous research $^{8}$ and contacts from departments of health, universities, HIV organisations and other non-government organisations in Australia and Southeast Asia.

\section{Sample size}

As the themes develop, theoretically driven sampling using a snowballing technique ${ }^{42}$ will be employed to ensure access to the social networks of the target groups. This will allow the researchers to examine and explore directions within the data that will bring about maximum returns, and to further develop and saturate the sampling categories originally identified. ${ }^{43}$ This sampling will become more theoretically driven and directed as the research progresses. ${ }^{43}$ Interviews and analysis will continue until saturation is reached on key areas under investigation and theory emerges and is developed from the data. ${ }^{43-45}$ Saturation is estimated to occur after the analyses of approximately 12 interviews if the participants are relatively homogeneous. ${ }^{45}$ While sample sizes in grounded theory studies are difficult to determine for the reasons described above, ${ }^{32}$ for this research, approximately 20 to 30 participants will be required.

\section{Data collection}

The primary data source will be interviews with key informants, though this will be supplemented through observation of some venues to increase researcher sensitivity and to validate interview data. It is anticipated that this will be conducted in several rounds in both Australia and Southeast Asia. Follow-up interviews may be required and undertaken once the initial data have been examined and themes developed. ${ }^{44}$ The follow-up may take place face to face or via telephone or email. Participation dropout rates will be recorded and reasons for non-participation will be explored.

There will be several phases of the research where multiple interviews and other data will be collected using a modified constant comparative approach. This will include data gathered in Thailand and the Northern Territory. During this time, interview data will be collected with reflection and comparison occurring after each day of data collection. This modified approach to grounded theory ${ }^{44}$ will enable reflection by an expert panel, immediate insights and provide multiple reflection points. It will also enable modification of the interview schedule in a formal debriefing setting for questions to be asked after each interview. This will maximise the potential of the data collection which may occur over a short period of time in the field.

\section{Interviews}

Guided interviews of approximately $1-2 \mathrm{~h}$ will be used owing to the flexibility of this technique. ${ }^{42}$ This technique provides a systematic and comprehensive approach to interviewing participants where clarification can be sought and gaps in the data can be addressed and closed. ${ }^{41}{ }^{42}$ Interview themes will be guided by the literature on symbolic interactionism, expatriate culture and social influence and consultation with informants and the steering group. Consistent with the grounded theory method, the content of the interviews may be modified over time to respond to emerging themes within the data. ${ }^{44}$ However, the initial enquiry domains for the interview guide, as outlined in box 1 below, will include data about the formation of networks and the roles that individuals play within networks.

Interviews will be digitally recorded for verbatim transcription. ${ }^{46}$ The interviewer will also complete relevant field notes and journals which are important processes in qualitative research. ${ }^{41} 42$

\section{Observation}

Where appropriate, the interview data will be supplemented with an audit of settings such as bars and online 


\section{Box 1 Initial interview domains of inquiry}

- The reasons for spending time away from Australia

- Whether they consider themselves to be an expatriate, and if so what this means

- When the participant considers themself to be an expatriate

- When others consider the participant to be an expatriate. This will explore issues of naming

- The influence of culture and socialisation among expatriates of their identity

- The meaning of country. What Australia means versus Southeast Asia to participants

- How the participant learnt the cultural and social norms within the country

- How expatriates and long-term travellers interact and create meaning from these interactions

- Who expatriates socialise with, and what social networks expatriates are part of

- Who the participant gained support from, and learnt from

- Who the participant feels they support or educate

- Personal behaviour among expatriates including participation in online networks and the way this behaviour differs 'at home' and 'away'

- Where participants feel risk is located. This will explore proximity

- To what extent a 'natural community' exists in the way it does in many groups that peer and social influence is used in Australia.

forums. Bars and entertainment precincts have been highlighted in previous research and interviews with key informants as locations regularly frequented by expatriates. ${ }^{8}$ Other social locations such as cafes or sporting clubs may be audited, based on the recommendations provided by research participants during the course of the interviews. It is difficult to determine the breadth of these potential locations and the viability to audit them until the research starts.

The purpose will be to compare audit findings to interview data and identify which spaces and settings contain qualities suitable for intervention. This process will enhance researcher sensitivity and allow the researcher to develop social and cultural meaning to support interview findings. ${ }^{47}$ Observation will provide an opportunity to examine processes of socialisation, including ritual and routine (such as attendance at particular social spaces and involvement in particular social activities) within the network. ${ }^{27}$ This may help to identify normalised behaviour within expatriate social networks, as well as behaviours which deviate from that deemed acceptable. The audit will use focused observations as a method of triangulating particular aspects of interview data and analysis. ${ }^{36} 47$ Field notes, researcher journals and photographs will be compiled for use during this process. ${ }^{46}$

\section{Analysis}

Data for this research will be analysed using the constant comparative approach. ${ }^{44}$ Constant comparison requires a comparison of interviews, and later the data to theory that is generated until a strong understanding of the phenomena of interest has emerged. This means data will be collected and analysed simultaneously. ${ }^{41}{ }^{44}$ The data analysis will comprise: data collection, ordering, organisation and explanation. ${ }^{44}$

As described above, symbolic interactionism will provide the overall analytical framework. Psychosocial theories which assist in understanding the qualities of communities or settings that support the use of peer education, peer support and social influence will also be assessed for their relevance. These theories could include Diffusion of Innovations Theory, ${ }^{48}$ Social Cognitive Theory ${ }^{49}$ and Social Identity Theory, ${ }^{50}$ which are broadly consistent with the symbolic interactionism framework.

Once data have been collected, they will be transcribed into a document compatible for use with computer-based word processing. Interviews will be transcribed in a manner that will maintain the confidentiality of the participants. ${ }^{40}$ The data that are collected will be systematically managed..$^{51}$ Computer-assisted data analysis will be used to enhance the management, storage, coding, retrieval comparison and linkage of data. ${ }^{32}$ For the purposes of this research, the NVivo V.10 qualitative software will be used.

\section{ETHICS AND DISSEMINATION}

This research has received approval from the Curtin University Human Research Ethics Committee, conforming to the National Statement on Ethical Conduct in Human Research. ${ }^{40}$ Participants will be informed that they are free to withdraw from the interview at any time and that in reporting, participant responses will be de-identified.

Safety is a consideration for this study. Data collection in Thailand and the Northern Territory will be conducted by a team of both male and female researchers who will provide support and debriefing to the primary researcher and assist in developing protocols to address issues of concern.

Research that examines challenging or sensitive issues may involve risk. Clear protocols are required to deal with a participant's distress. ${ }^{40}$ In collaboration with the research steering group, the researcher will develop guidelines to identify distress and develop appropriate referral pathways. The researcher will liaise with relevant organisations in Australia and Southeast Asia to provide assistance to any participant on issues arising during the course of the interview including sexual health, sexuality, alcohol and other drug use or other emotional or physical health issues.

The role of expatriate and long-term traveller networks and their potential to impact health are untested. This is a new area of research which provides the opportunity to develop novel ways of thinking about the application of grounded theory and sense-making about 
changes to the HIV epidemic and those at risk. The chosen methodology can develop typologies to gain insight into expatriate and traveller behaviour. Further, it can illustrate how to locate and identify champions as change agents to address key health and social issues experienced by expatriates and longer term travellers.

This study will develop recommendations for government, non-government and research organisations regarding intervention methods. The research provides an opportunity for publications arising over the course of the study. This includes a literature review, findings regarding expatriate culture and personal behaviour and an exploration of expatriates as mentors and potential change agents. Findings from the research will be disseminated to health professionals and other stakeholders, academics and community via local research, and evaluation networks, conference presentations and online forums.

It is anticipated that a more cohesive and national response to the issue of HIV and mobility will be forthcoming including funding for research at a national and state level. Travellers will continue to be a key priority population for the next Australian national HIV strategy and the current study can provide context and tangible outcomes for research, policy and practice.

Acknowledgements The authors would like to acknowledge Lisa Bastian and Jonathan Hallett for their review of this paper and Trish Langdon for her support of this research.

Contributors All authors listed above fulfil all three of the International Committee of Medical Journal Editors (ICMJE) guidelines for authorship which are: (1) substantial contributions to conception and design, acquisition of data or analysis and interpretation of data; (2) drafting the article or revising it critically for important intellectual content and (3) final approval of the version to be published. GC was responsible for coordinating the contribution of all authors to this paper. All authors made significant contributions to the development and conceptualisation of the protocol. $\mathrm{GC}$ and NB were responsible for drafting this paper. GB and BM were responsible for editing and guidance on the paper. All authors were responsible for critically revising the paper. All authors approved the final version of this paper for submission.

Funding This work is supported in part by funding from the Department of Health Western Australia (one off funding via the Western Australian AIDS Council, Agreement Number: C04403) and the Department of Health and Families Northern Territory (one off funding via a Public Health Outcomes Funding Agreement with the Sexual Health \& Blood Borne Virus Unit, Contract Number: CTR-MM-04227-1). Views articulated in this article are those of the authors and not necessarily those of the funding agencies.

Competing interests None.

Ethics approval Curtin University Human Research Ethics Committee.

Provenance and peer review Not commissioned; internally peer reviewed.

\section{REFERENCES}

1. Commonwealth of Australia. Sixth national HIV strategy 2010-2013. Canberra: Commonwealth of Australia, 2010.

2. Benard D, Kippax S, Baxter D. Effective partnership and adequate investment underpin a successful response: key factors in dealing with HIV increases. Sex Health 2008;5:193-201.

3. Guy RJ, McDonald AM, Bartlett MJ, et al. HIV diagnoses in Australia: diverging epidemics within a low-prevalence country. Med J Aust 2007; 187:437-40.
4. Combs BC, Giele CM. An increase in overseas acquired HIV infections among heterosexual people in Western Australia. Sex Health 2009;6:35-9.

5. The Kirby Institute. HIV, viral hepatitis and sexually transmissible infections in Australia annual surveillance report 2012. Sydney: The Kirby Institute, the University of New South Wales, 2012.

6. Department of Health Western Australia. The epidemiology of notifiable sexually transmitted infections and blood-borne viruses in Western Australia 2010. Canberra: Department of Health Western Australia, 2010.

7. Australian Bureau of Statistics. 3401.0-Overseas arrivals and departures, Australia, 2012. http://www.abs.gov.au (accessed 20 Jun 2012).

8. Brown G, Ellard J, Mooney-Somers J, et al. HIV risk among Australian men travelling overseas: networks and context matter. Cult Health Sex 2012;14:677-90.

9. Down I, Triffitt K, Persson A, et al. Experiences of HIV: the seroconversion study report 2012. Sydney: The Kirby Institute, the University of New South Wales, 2012.

10. Clift S, Carter S. Tourism and sex: culture, commerce and coercion. London: Cengage, 2000.

11. Wilson D, Halperin DT. Know your epidemic, know your response: a useful approach, if we get it right. Lancet 2008;372:423-6.

12. Coates TJ, Richter $L$, Caceres $C$. Behavioural strategies to reduce HIV transmission: how to make them work better. Lancet 2008;372:669-84.

13. De Graaf $R$, Zessen GV, Houweling $H$. Underlying reasons for sexual conduct and condom use among expatriates posted in AIDS endemic areas. AIDS Care 1997;10:651-65.

14. Houweling $\mathrm{H}$, Coutinho RA. Risk of HIV infection among Dutch expatriates in sub-Saharan Africa. Int J STD AIDS 1991;2:252-7.

15. Vivancos R, Abubakar I, Hunter PR. Foreign travel, casual sex, and sexually transmitted infections: systematic review and meta-analysis. Int J Infect Dis 2010;14:e842-51.

16. Yokota F. Sex behaviour of male Japanese tourists in Bangkok, Thailand. Cult Health Sex 2006;8:115-31.

17. Howard RW. Risky business? Asking tourists what hazards they actually encountered in Thailand. Tourism Manag 2009;30:359-65.

18. Tucker JS, Hu J, Golinelli D, et al. Social network and individual correlates of sexual risk behaviour among homeless young men who have sex with men. $J$ Adolesc Health 2012;51:386-92.

19. Mackenzie S, Pearson C, Frye V, et al. Agents of change: peer mentorship as HIV prevention among HIV-positive injection drug users. Subst Use Misuse 2012;47:522-34.

20. Garfein RS, Golub ET, Greenberg AE, et al. A peer-education intervention to reduce injection risk behaviors for HIV and hepatitis $C$ virus infection in young injection drug users. AIDS 2007;21:1923-32.

21. Fuqua V, Chen $Y$, Packer T, et al. Using social networks to reach black MSM for HIV testing and linkage to care. AIDS Behav 2012;16:256-65.

22. Blumer H. Symbolic interactionism: perspective and method. Upper Saddle River, NJ: Prentice-Hall, 1969.

23. Charon JM. Symbolic interactionism: an introduction, an interpretation, an integration. 7th edn. Englewood Cliffs: Prentice Hall, 2001.

24. Crotty M. The Foundations of Social Research: meaning and perspective in the research process. St Leonards: Allen and Unwin, 1998.

25. Liamputtong P. Qualitative research methods. Sydney: Oxford University Press, 2009.

26. Klunklin A, Greenwood J. Symbolic interactions in grounded theory studies: women surviving with HIV/AIDS in rural northern Thailand $J$ Assoc Nurses AIDS Care 2006;17:32-41.

27. Denzin NK. The methodological implications of symbolic interactionism for the study of deviance. Br J Sociol 1974:25:269-82.

28. Glaser B, Strauss A. The discovery of grounded theory. Chicago: Aldine, 1967.

29. Corbin J, Strauss AL. Grounded theory research: procedures canons and evaluative criteria. Qual Sociol 1990;13:3-21.

30. Glaser BG, Strauss AL. Awareness of dying. Chicago: Aldine, 1965.

31. Dey I. Grounding categories. In: Bryant A, Charmaz K, eds. The SAGE handbook of grounded theory. London: SAGE Publications, 2007:167.

32. Liamputtong P. Qualitative research methods. 4th edn. New York: Oxford University Press, 2013.

33. Tong A, Sainsbury P, Craig J. Consolidated criteria for reporting qualitative research (COREQ): a 32 -item checklist for interviews and focus groups. Int J Qual Health Care 2007;19:349-57.

34. Agustin C. How can reporting guidelines help you write your research findings? Radiographer 2009;56:5-9. 
35. Schulz KF, Altman DG, Moher D, et al. CONSORT 2010 statement: updated guidelines for reporting parallel group randomized trials. Ann Intern Med 2010;152:726-32.

36. Kitto SC, Chesters J, Grbich C. Quality in qualitative research: criteria for authors and assessors in the submission and assessment of qualitative research articles for the Medical Journal of Australia. Med J Aust 2008;188:243-6.

37. Engvall G, Cernvall M, Larsson G, et al. Cancer during adolescence: negative and positive consequences reported three and four years after diagnosis. PLOS one 2011;6:1-5.

38. Meurer WJ, Majersik JJ, Frederiksen SM, et al. Provider perceptions of barriers to the emergency use of tPA for acute ischemic stroke: a qualitative study. BMC Emerg Med 2011;11:1-12.

39. Neubeck L, Freedman SB, Clark AM, et al. Participating in cardiac rehabilitation: a systematic review and meta-synthesis of qualitative data. Eur J Cardiovasc Prev Rehabil 2011;19:494-503.

40. National Health and Medical Research Council, Australian Research Council, Australian Vice-Chancellors' Committee. National statement on ethical conduct in human research. Canberra: Australian Government, 2007.

41. Patton M. Qualitative research and evaluation methods. London: Sage Publications, 2002.

42. Grbich C. Qualitative research in health: an introduction. St. Leonard's: Allen and Unwin, 1999.
43. Strauss A, Corbin J. Basics of qualitative research: techniques and procedures for developing grounded theory. 2nd edn. Thousand Oaks: Sage Publications, 1998.

44. Corbin J, Strauss A. Basics of qualitative research 3e. United States of America: Sage Publications, 2008

45. Guest G, Bunce A, Johnson L. How many interviews are enough? An experiment with data saturation and variability. Field Methods 2006;18:59-82.

46. Bourgeault I, Dingwall R, De Vries R. The SAGE handbook of qualitative methods in health research. London: SAGE Publications, 2010.

47. Maycock BR, Howat P. Social capital: implications from an investigation of illegal anabolic steroid networks. Health Educ Res 2007:22:854-63.

48. Rogers EM. Diffusion of innovations. New York: Free Press, 1983.

49. Bandura A. Social learning theory. New Jersey: Prentice Hill, 1997.

50. Taifel $\mathrm{H}$, Turner J. An integrative theory of intergroup conflict. In: Austin WG, Worchel S, eds. The social psychology of intergroup relations. Monterey: Brooks-Cole, 1979:33-47.

51. McLellan E, MacQueen KM, Neidig JL. Beyond the qualitative interview: data preparation and transcription. Field methods 2003;15:63-86. 